\title{
Measurement and modeling of soil water regime in a lowland paddy field showing preferential transport
}

\author{
Kaushal K. Garg a, Bhabani S. Das ${ }^{\text {b,* }}$, Mohammad Safeeq ${ }^{\text {c }}$, Pratap B.S. Bhadoria ${ }^{\text {b }}$ \\ a International Crop Research Institute for the Semi-Arid Tropics (ICRISAT), Pathancheru, Hyderabad, AP, India \\ ${ }^{\mathrm{b}}$ Agricultural and Food Engineering Department, Indian Institute of Technology, Kharagpur 721302, W.B., India \\ ${ }^{\mathrm{c}}$ Sherman Lab, 242, 1910 East West Rd., Honolulu, HI 96822, USA
}

A R T I C L E I N F O

\section{Article history:}

Received 9 April 2008

Accepted 26 June 2009

Available online 19 August 2009

\section{Keywords:}

Lowland paddy soil

Puddling

Plow sole

Hydraulic properties

Single-porosity model

Preferential flow

\begin{abstract}
A B S T R A C T
Paddy is commonly grown under flooded or submerged condition in which substantial amount of water is lost by different processes. Puddling is traditionally done to reduce water loss from lowland rice fields. Since the very step of puddling, rice root zone undergoes structural changes leading to the formation of a layered profile having a hydraulically less-conductive plow sole below the root zone. However, studies have shown that soil cracking and the presence of preferential flow paths in puddle fields defeat this purpose. Description of soil water regime in such a dynamic soil requires an in situ measurement method for soil hydraulic properties. A field experiment was conducted in twelve $30 \mathrm{~m}^{2}$ plots during the rainy seasons (June to October) of 2004 and 2005 to evaluate a suitable method for estimating soil hydraulic properties of lowland paddy soil. Results showed that piezometric (pressure) heads installed in different soil layers responded to the drying and wetting cycles typically followed in transplanted rice and are observed as a part of monsoon climate in eastern India. The Marquardt-Levenberg algorithm built in the HYDRUS-1D simulation environment was used to inversely estimate soil hydraulic parameters. Estimated parameters revealed larger hydraulic conductivity for the compacted plow sole than those published in literature, which may have resulted from alternate wetting and drying typically observed under monsoon climate and earthworm burrows observed in our experimental field. Results from simulation studies suggest that both the single- and dual-porosity models could simulate water flow considerably well in lowland paddy field although the latter described pressure head time series data slightly better in about $50 \%$ of simulations. Similar performance of the single- vs. dual-porosity model may have resulted from estimating a seasonally mean soil hydraulic properties which include the effect of both preferential flow and matrix flow as the specific soil and boundary conditions prevailed. While water may have preferentially transported through the macropores during the wetting cycles in a nearsaturated soil, it would have dominantly moved through soil matrix during the drying cycles. This study shows that simple piezometers may be combined with a simulation model to estimate hydraulic properties of different soil layers in a lowland paddy field.
\end{abstract}

() 2009 Elsevier B.V. All rights reserved.

\section{Introduction}

In India, paddy (Oryza sativa) is grown over an area of 43 million ha with an annual production of 124 million tons (IRRI, 2004) and average productivity is only $2-3.5$ tons/ha (Ladha et al., 2000). Two major management constraints in lowland paddy production systems are poor use efficiencies for water and nitrogen $(\mathrm{N})$. The water use efficiency (WUE) for transplanted rice is only 20-30\% (Walker and Rushton, 1984; Tuong and Bhuiyan, 1999). Similarly, N use efficiency (NUE) is 20-40\% (Vlek et al., 1980; De Datta, 1987; Raun and Johnson, 1999). Generally, a substantial amount of

\footnotetext{
* Corresponding author. Tel.: +91 3222 283162; fax: +91 3222282244.

E-mail address: bsdas@iitkgp.ac.in (B.S. Das).
}

applied water is lost during land preparation of soil from bypass flow through cracks (Cabangon and Tuong, 2000), by deep percolation from root zone, seepage through bunds (Janssen and Lennartz, 2007, 2008), and evapotranspiration (Hardjoamidjojo, 1992; Sharma and De Datta, 1992; Humphreys et al., 1992). Wopereis et al. (1994) estimated cumulative seepage and percolation (SP) losses during a crop cycle for a well-puddled paddy field alone to be as high as $350 \mathrm{~cm}$. With such large quantity of water loss, the leaching of nitrogenous fertilizers may be a major reason for poor NUE in lowland paddy. Therefore, efforts to develop efficient water management techniques may improve both WUE and NUE in lowland paddy.

Puddling is traditionally done to reduce percolation losses from lowland paddy fields. Typically, it promotes the formation of a layered profile consisting of a slurry-like puddled top soil layer, a 
hydraulically less-conductive middle layer (also, called plow sole), and a less compact subsoil layer below the plow sole (Tuong et al., 1994). Hydraulic properties of plow sole dominantly control the water regime of puddled paddy fields (Wopereis et al., 1994; Tuong et al., 1994; Chen and Liu, 2002) often forming an unsaturated zone below the plow sole (Takagi, 1960; Wopereis et al., 1992; Tournebize et al., 2006). In paddy fields of eastern India, alternate wetting (ponding) and drying (drainage) is a natural phenomenon because of the occurrence of frequent dryspells and intense rainfall as a part of monsoon climate during the Kharif (July to October) season (Panigrahi et al., 2001). Wetting and drying conditions result in unsaturated soil water regime in paddy soils. Moreover, typical water-saving schemes in paddy production systems involve alternate wetting and drying conditions in lowland paddy soils (Tabbal et al., 2002; Belder et al., 2007) leading to unsaturated soil water regimes. Recently, Yang et al. (2007) showed 7-11\% increase in yield with up to $38 \%$ reduction in irrigation water by maintaining critical soil water potential (SWP) at $-15 \mathrm{kPa}$. Understanding of soil water movement in lowland paddy soils is an important step to effectively maintain a critical SWP (unsaturated soil water regime) in paddy root zone.

The structural changes in rice root zone since the very first step of puddling yield a dynamic and transient rice rhizosphere. Moreover, rice soils are known to crack (Tournebize et al., 2006) under drying and wetting cycles leading to the formation of preferential flow paths (Janssen and Lennartz, 2007, 2008, 2009). In eastern Indian paddy soils, profuse earthworm casts are a common feature, which are known to entail preferential transport. In view of the poor water and nitrogen efficiency in rice production system, the dynamic nature of paddy rhizosphere have drawn renewed interest (Janssen and Lennartz, 2007, 2008, 2009). During the last decade, a few field-scale water flow studies have shown that the Richards equation may be applied to describe water flow in puddled paddy fields (Wopereis et al., 1992, 1994; Tuong et al., 1994; Liu et al., 2001; Chen et al., 2002; Tournebize et al., 2006). Solution to Richards equation requires soil hydraulic properties in addition to appropriate boundary and initial conditions. In general, soil hydraulic properties vary both in space and in time; the variation is large under field conditions. Such variations pose a challenge for devising a robust measurement method for soil hydraulic properties for the field-scale. Soil layering in lowland paddy soils poses added difficulty in obtaining these properties. Specifically, an in situ measurement method for hydraulic properties for different soil layers in a puddled paddy field has not been reported. Thus, the objective of this study was to estimate soil hydraulic properties and model water flow in the layered lowland paddy fields. The Marquardt-Levenberg algorithm built in the HYDRUS-1D simulation environment (Simunek et al., 1999) was used for modeling the experimental data.

\section{Materials and methods}

\subsection{Field experiment}

The field experiment consisted of growing paddy (var. IR-36, duration 110 days) during the Kharif season of 2004 and 2005 in twelve $6 \mathrm{~m} \times 5 \mathrm{~m}$ plots (Fig. 1) at the experimental farm of Agricultural and Food Engineering Department, Indian Institute of Technology, Kharagpur $\left(22^{\circ} 19^{\prime} \mathrm{N}, 87^{\circ} 19^{\prime} \mathrm{E}\right)$, India. Mean annual rainfall at this site ranges from 1400 to $1600 \mathrm{~mm}$ with about $70 \%$ distributed over the months of July to October. Soils in this region are lateritic (Haplustalf) with the presence of a discontinuous clay pan below $80 \mathrm{~cm}$ depth. Table 1 shows different physical and chemical properties of soil layers for this site.

Twenty days old paddy seedlings were transplanted after the top soil $(0-15 \mathrm{~cm})$ was puddled. Three nitrogen treatments (T1: 80; T2: 160 ; and T3: $240 \mathrm{~kg} \mathrm{~N} /$ ha in the form of urea) with four replications were laid out in a completely randomized design. Data pertaining to the nitrogen transport in this field is reported elsewhere (Garg, 2007). Recommended dose of phosphate (30 kg/ ha) and potash (40 kg/ha) was applied during puddling. About $3.3 \mathrm{~cm}$ of ponded water (equivalent to $1000 \mathrm{~L}$ of water per plot) was maintained during first 10 weeks after transplanting. Efforts were made to maintain a continuous ponded condition during 2005 by frequently irrigating the field as compared to the 2004 experiment. Soil water contents were measured in surface soils ( 0 $5 \mathrm{~cm}$ depth) collected from a few plots when the plots were unsaturated following zero ponding conditions.

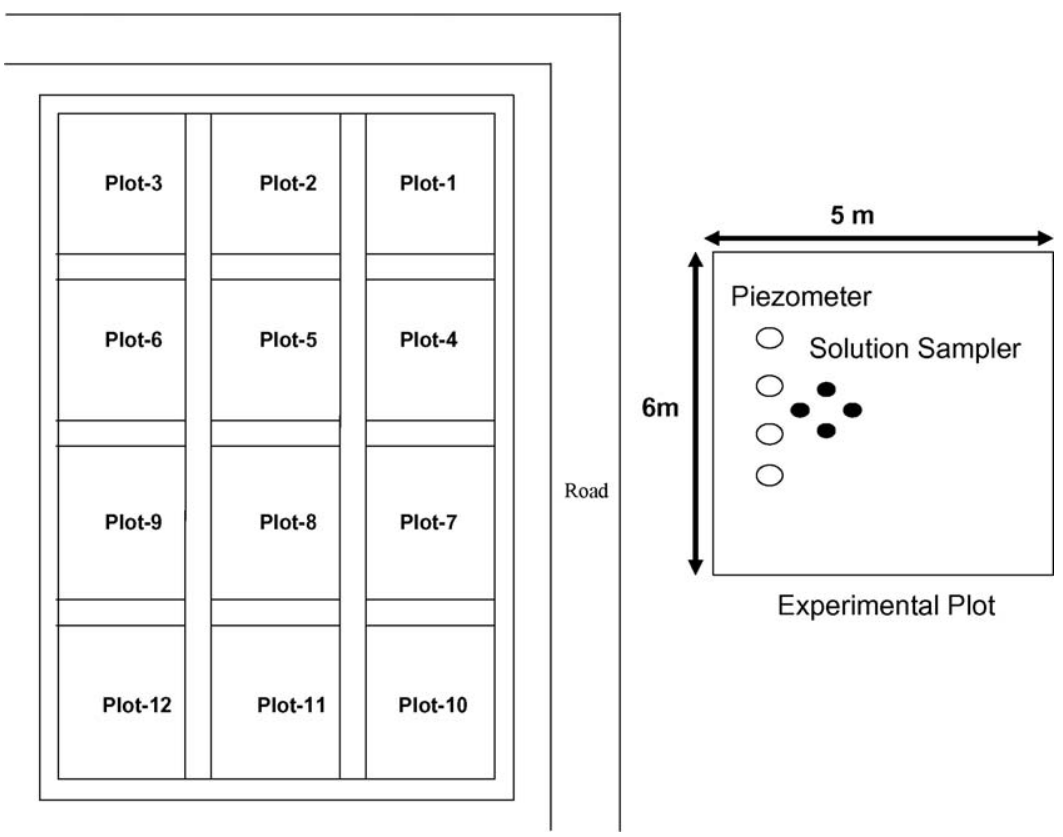

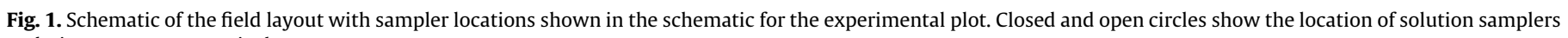
and piezometers, respectively. 
Table 1

Basic soil properties of different soil layers.

\begin{tabular}{lllll}
\hline $\begin{array}{l}\text { Soil depth } \\
(\mathrm{cm})\end{array}$ & $\begin{array}{l}\text { Bulk density } \\
\left(\mathrm{g} \mathrm{cm}^{-3}\right)\end{array}$ & $\begin{array}{l}\text { Organic carbon } \\
\text { content (\%) }\end{array}$ & $\begin{array}{l}\text { Sand } \\
\text { content }(\%)\end{array}$ & $\begin{array}{l}\text { Clay } \\
\text { content (\%) }\end{array}$ \\
\hline 5 & $1.49(4.55)^{\mathrm{a}}$ & $2.6(30.6)$ & 61.3 & 21.1 \\
15 & $1.79(2.78)$ & $1.3(39.1)$ & 55.9 & 24.5 \\
35 & $1.66(6.46)$ & $0.7(35)$ & 42.8 & 35.0 \\
55 & $1.59(3.53)$ & ND & 43.8 & 34.4 \\
80 & $1.69(2.59)$ & ND & 48.2 & 37.7 \\
\hline
\end{tabular}

ND, not determined.

a Values in the parenthesis indicate the coefficients of variation (CV) expressed in percentage.

Before transplanting, piezometers were installed in each plot at $20,40,60$, and $80 \mathrm{~cm}$ soil depths to monitor daily pressure head values using an electronic water level indicator. After harvesting paddy in the year 2004, the plots were left fallow until 2005 summer. Before taking up the rice crop in 2005, tension infiltrometer (TI) test were carried out during April to June 2005 in the same experimental plots. Both transient- and steady-state water fluxes were recorded within each plot. Each set of TI measurements was carried out by maintaining different water tensions $(-16,-10,-5,-3$, and $-1 \mathrm{~cm})$. About $8-12 \mathrm{~h}$ were required to complete a set of TI measurements at a given location. Soil cores were collected both before and after each TI test from adjacent and from the measuring location to determine initial and final volumetric water contents in surface soil $(0-5 \mathrm{~cm}$ soil depth). In a few plots (Plots 3, 5, 7, 9, and 10), multiple TI measurements were made to test the hypothesis of preferential flow. These locations had a separation distance of 1-2 $\mathrm{m}$.

\subsection{Modeling of water flow in variably saturated soil}

\subsubsection{Single-porosity model (SPM) and dual-porosity model (DPM) for water flow}

Both the single-porosity and dual-porosity modeling approaches were applied to estimate soil hydraulic properties. The SPM approach assumes that the entire flow domain actively conducts water according to Richards equation:

$\frac{\partial \theta}{\partial t}=\frac{\partial}{\partial Z}\left\{K(\psi)\left(\frac{\partial \psi}{\partial z}+1\right)\right\}$

where $t$ is time (h), $\theta$ is the volumetric water content $\left(\mathrm{cm}^{3} \mathrm{~cm}^{-3}\right), \psi$ is the soil matric potential head $(\mathrm{cm})$, and $z$ is the spatial coordinate (cm) defined as positive upward. We used van Genuchten's $K-\psi$ and $\theta-\psi$ relationships for describing soil hydraulic properties of lowland paddy soils (van Genuchten, 1980):

$\theta(\psi)=\theta_{\mathrm{r}}+\frac{\theta_{\mathrm{s}}-\theta_{\mathrm{r}}}{\left\{1+(\alpha \psi)^{n}\right\}^{m}}, \quad \psi \leq 0$

$K(\psi)=K_{\mathrm{s}} S_{\mathrm{e}}^{l}\left(1-\left(1-S_{\mathrm{e}}^{1 / m}\right)^{m}\right)^{2}$

with

$m=1-\frac{1}{n} \quad$ and $\quad S_{\mathrm{e}}=\frac{\theta-\theta_{\mathrm{r}}}{\theta_{\mathrm{s}}-\theta_{\mathrm{r}}}$

where $\theta_{\mathrm{r}}$ and $\theta_{\mathrm{s}}$ denote the residual and saturated volumetric water contents $\left(\mathrm{cm}^{3} \mathrm{~cm}^{-3}\right)$, respectively; $\alpha\left(\mathrm{cm}^{-1}\right)$ and $n(-)$ are fitting parameters of soil water characteristic curve; $l(-)$ is the pore connectivity parameter $(=0.5)$; and $S_{\mathrm{e}}(-)$ is the relative saturation.

The DPM approach assumes that water flow is restricted to the fractures (or inter-aggregate pores and macropores) and that water in the matrix (intra-aggregate pores) is immobile (Simunek et al., 2003). The total water content $(\theta)$ of a soil is thus the sum of the water present in the intra-aggregate pores $\left(\theta_{\mathrm{im}}\right)$ and that present in the macropores $\left(\theta_{\mathrm{m}}\right)$. The DPM formulation for water flow can be based on a mixed formulation of the Richards equation (Simunek et al., 2003):

$$
\begin{aligned}
& \frac{\partial \theta_{\mathrm{m}}}{\partial t}=\frac{\partial}{\partial z}\left[K(h)\left(\frac{\partial h}{\partial z}+1\right)\right]-S_{\mathrm{m}}-\tau_{\mathrm{w}} \\
& \frac{\partial \theta_{\mathrm{im}}}{\partial t}=-S_{\mathrm{im}}+\tau_{\mathrm{w}} \\
& \tau_{\mathrm{w}}=\omega\left(h_{\mathrm{m}}-h_{\mathrm{im}}\right)
\end{aligned}
$$

where $S$ is the sink term and $\omega$ is the mass transfer rate $\left(\mathrm{h}^{-1}\right)$ for water from the inter to intra-aggregate pores. Subscript ' $m$ ' denotes the macropore (mobile) domain and 'im' denotes the matrix domain. In this modeling approach, total eight parameters $\left(\theta_{\mathrm{rim}}, \theta_{\mathrm{rm}}, \theta_{\mathrm{sm}}, \theta_{\mathrm{sim}}, n, \alpha, K_{\mathrm{s}}\right.$, and $\left.\omega\right)$ are needed. The parameters $\theta_{\mathrm{rm}}$ and $\theta_{\text {rim }}$ are the residual water content for mobile and immobile region, respectively; $\theta_{\mathrm{sm}}$ and $\theta_{\text {sim }}$ are the total pore volume for mobile and immobile phases, respectively; and $K_{\mathrm{s}}, n$, and $\alpha$ are the fitting parameters of water characteristic curve for mobile phase.

\subsubsection{Estimation of soil hydraulic properties using pressure head data}

Soil hydraulic properties of 12 experimental plots were estimated using the inverse optimization option of the HYDRUS1D model. Marquardt-Levenberg type parameter estimation algorithm is implemented in HYDRUS-1D for inverse estimation of selected soil hydraulic parameters. Based on measured soil bulk densities, soil profiles in each plot were divided into four layers, i.e., $0-10,10-26,26-52$, and $52-80 \mathrm{~cm}$. The top of the surface soil layer (0-10 cm depth) was considered as the upper surface boundary and the $80 \mathrm{~cm}$ depth was arbitrarily taken as the bottom boundary of the flow domain. Simulations were done by assigning atmospheric boundary condition at the soil surface and a variable pressure head (as measured by the piezometer installed at $80 \mathrm{~cm}$ depth) at the bottom boundary of the flow domain. Measured values of daily rainfall plus irrigation, potential evapotranspiration, and the pressure head data at $80 \mathrm{~cm}$ soil depth were provided as inputs during optimization. No runoff was considered from soil surface because about $2 \mathrm{~m}$ wide and $0.3 \mathrm{~m}$ high bunds were provided around each experimental plot. Because bunds were freshly laid just before the 2004 experiment during the field layout, we expected minimal seepage and percolation at least for 2004 experiment. Each bund was also polished with fresh mud before transplanting in each growing season. Water pressure head values measured at 20,40, and $60 \mathrm{~cm}$ soil depths were used as the auxiliary variable in the objective function. Hence, 72 sets of time series data (3 depths, 12 plots, and 2 growing seasons) for piezometric heads were used to estimate soil hydraulic properties at $0-10,10-26,26-52$, and $52-80 \mathrm{~cm}$ soil layers. Soil hydraulic properties for the first two layers were estimated simultaneously using the pressure head data collected at $20 \mathrm{~cm}$ soil depth as no separate piezometers were installed at $0-10$ and $10-26 \mathrm{~cm}$ depths. Hydraulic properties for $26-52$ and $52-80 \mathrm{~cm}$ soil layers were estimated using the pressure head data collected from 40 and $60 \mathrm{~cm}$ depths, respectively. Thus, altogether 48 sets ( 4 depths and 12 plots) of soil hydraulic properties were estimated each year.

Parameter uniqueness is a major issue in inverse optimization method. Typically, additional data are provided along with the auxiliary variable for obtaining reliable estimates of hydraulic properties in this method (Simunek and van Genuchten, 1997). We only had fewer data points on surface water contents and we did not observe significant change in parameter estimates when these water contents were used in the objective function. Thus, surface water contents were not used during optimization. Rather, we tried to optimize less number of parameters. For all the soil layers, saturated water contents were equated to porosity and were 
treated as known parameters. Similarly, saturated hydraulic conductivity $\left(K_{\mathrm{s}}\right)$ for all surface soils $(0-10 \mathrm{~cm})$ were obtained by fitting the Gardner's exponential model for the unsaturated hydraulic conductivity $\left[K(h)=K_{\mathrm{s}} \exp (b h)\right]$ function to steady-state water fluxes at different supply pressures. Thus, we estimated $\theta_{\mathrm{r}}, n$, and $\alpha$ for the surface soil layer and $\theta_{\mathrm{r}}, n, \alpha$, and $K_{\mathrm{s}}$ for the remaining 3 subsurface layers in the SPM approach.

Similarly, we estimated only three parameters for the surface soil layers and four parameters for the subsurface layers out of total eight parameters $\left(\theta_{\mathrm{rim}}, \theta_{\mathrm{rm}}, \theta_{\mathrm{sm}}, \theta_{\mathrm{sim}}, n, \alpha, K_{\mathrm{s}}\right.$, and $\left.\omega\right)$ in the DPM approach. To do this, we first assumed that both $\theta_{\mathrm{rm}}$ and $\theta_{\mathrm{rim}}$ are negligible in view of the coarse textured soils. This led to the constraint that $\theta_{\mathrm{sm}}+\theta_{\mathrm{sim}}=\theta_{\mathrm{s}}$. We conducted several preliminary simulations and observed that the $\theta_{\mathrm{sm}}$ values were about $30 \%$ of total porosity. Thus, we assumed that $\theta_{\text {sim }}=0.7 \times$ porosity. Thus, the remaining four parameters were directly optimized. Similar to the SPM approach, $K_{\mathrm{s}}$ for the surface soils were estimated from the TI data.

\subsubsection{Estimation of soil hydraulic properties using TI data}

Transient water fluxes from the TI data were also modeled using both the modeling approaches by selecting the cumulative flux in the objective function for optimization. Variable matric potential heads (= equilibrium supply pressure at the TI membrane) were used as the upper boundary conditions and deep drainage was selected as the lower boundary conditions. Initial and final volumetric water contents at surface soil were also provided as inputs to the HYDRUS model. The layered soil profile could not be used because it required too many parameters (12 parameters each in the SPM and DPM approach) to be estimated utilizing limited number of water flux data generally taken in an infiltration experiment. Therefore, we used a uniform soil profile of $80 \mathrm{~cm}$ thickness and a uniform porosity estimated from depth-averaged soil bulk density for each plot. Thus, these parameters represent only the average hydraulic behavior of the $80 \mathrm{~cm}$ deep profile. Such a consideration precluded layer-wise comparison of soil hydraulic properties with those obtained from piezometric data.

\subsubsection{Estimation of macroporosity}

Extent of water loss through preferential pathways was also estimated using the Watson and Luxmoore (1986) approach. Pore radii for imposed suction on TI membranes were estimated using the capillarity equation:

$r=-\frac{2 \sigma}{\sigma g h}$

where $\sigma$ is the surface tension of water, $\rho$ is the density of water, $g$ is the constant acceleration due to gravity, and $h$ is the suction imposed on TI disc. Macropore conductivity $\left(K_{\mathrm{m}}\right)$ was determined as the difference between the ponded-infiltration rate and infiltration rate at any tension head (Watson and Luxmoore, 1986). Using the minimum pore radius ( $r$ ) and applying Eq. (8) in conjunction with Poiseuille's equation, the maximum number of effective macropores per unit area was calculated by

$N=\frac{8 \mu K_{\mathrm{m}}}{\pi \rho g r^{4}}$

where $\mu$ is the viscosity of water. The water conducting porosity $\left(\theta_{\mathrm{m}}\right)$ was then estimated using the relationship:

$\theta_{m}=N \pi r^{2}$

Total water conducting porosities $\left(\theta_{\mathrm{mt}}\right)$ were estimated by summing up $\theta_{\mathrm{m}}$ values for imposed tensions from 0 to $-16 \mathrm{~cm}$. Similarly, the contribution of macropore flow $(M F)$ was estimated using the relationship:

$\operatorname{MF}(\%)=\frac{q_{0}-q_{-16}}{q_{0}} \times 100$

where $q_{0}$ and $q_{-16}$ are the steady-state water fluxes at 0 and $-16 \mathrm{~cm}$ tensions, respectively. Eq. (11) accounts for both macropore $(h>-4 \mathrm{~cm})$ and mesopore $(-16 \mathrm{~cm}<h<-4 \mathrm{~cm})$.

\subsubsection{Model performance}

Model performance was assessed by comparing the predicted and measured pressure heads using the root-mean-squared error (RMSE) of prediction:

RMSE $=\sqrt{\frac{1}{n-p} \sum_{i=1}^{n}\left(x_{i}-y_{i}\right)^{2}}$

where $n$ is the number of data points of measured $\left(x_{i}\right)$ and calculated $\left(y_{i}\right)$ pressure head and $p$ is the number of parameters estimated during optimization. Several validation exercises were carried out to establish the predictability of a set of hydraulic properties. For example, soil hydraulic parameters derived by the piezometric data in 2004 were used as input to predict the pressure head during 2005 and vice versa. Similarly, average soil hydraulic properties of first six plots were calculated and used to predict the pressure heads for other six plots and vice versa. Average soil hydraulic parameters of experimental site were also used to simulate the pressure head in next or previous year. Soil hydraulic properties estimated from the TI data were also used to predict pressure head data for both years.

\section{Results and discussion}

\subsection{Basic soil properties of experimental plots}

Table 1 shows the mean values for soil bulk density $\left(\rho_{\mathrm{b}}\right)$, organic carbon (OC), sand and clay contents estimated from different soil layers in experimental plots. While $\rho_{\mathrm{b}}$ and OC were measured in all the 12 plots, soil texture was determined only in Plot 3 and 8 . This table shows that the soil layer around $15 \mathrm{~cm}$ depth has the highest $\rho_{\mathrm{b}}$ with a range from 1.74 to $1.86 \mathrm{~g} \mathrm{~cm}^{-3}$. Soils above and below this layer were generally less compact. Table 1 also suggests that soils at this site are less variable in horizontal than vertical direction with respect to $\rho_{\mathrm{b}}$. Sieve analysis of soils collected at $15 \mathrm{~cm}$ interval from a single profile showed that the soil layers at a depth of $22.5 \mathrm{~cm}$ had highest percentage of soil particles with diameter $<0.075 \mathrm{~mm}$ (data not shown). This is a common feature with the puddled paddy soils (Tuong et al., 1994) - puddling operation promotes illuviation of finer soil fractions to form a compact plow sole. Increasing clay contents with soil depth (Table 1) supports this result. Another typical feature of this Kharagpur soil is the presence of a discontinuous clay pan at about $1 \mathrm{~m}$ soil depth as is evident from the higher range in $\rho_{\mathrm{b}}\left(1.63-1.77 \mathrm{~g} \mathrm{~cm}^{-3}\right)$ and maximum clay contents observed at $80 \mathrm{~cm}$ soil depth. The presence of plow sole and compact layers at deeper soil depths may lead to the development of two perched layers of water (one above plow sole, and the other above the clay pan) within the top $1 \mathrm{~m}$ of soil.

\subsection{Rainfall data, dryspell analysis, and irrigation requirement}

Analysis of rainfall data collected during the paddy growing seasons showed that a total of 79 and $91 \mathrm{~cm}$ of rainfall were received between 205th ( 2 days before transplanting) and 290th (10 days before harvest) days over a period of 84 days between July 25 and October 15 in the year 2004 and 2005, respectively. Total number of days with no rainfall was 22 in 2004 and 33 in 2005. Also, the number of dryspells with the duration of 3 days or longer was 4 for 2004 and 
6 for 2005. Accumulated potential evapotranspirations $\left(\mathrm{ET}_{0}\right)$ during this period were $31 \mathrm{~cm}$ in 2004 and $33 \mathrm{~cm}$ in 2005. Nonhomogeneity of rainfall (distribution and magnitude) did not allow soil to continuously saturate generating greater hydraulic gradient and equivalently more water loss during 2005 than 2004. Thus, despite more total rainfall in 2005 , more water was needed to maintain continuous flooding condition in 2005 than in 2004. Besides, we observed that even with high volume of irrigation water (Table 2 ), there were $>30$ days with no ponding water at soil surface in 2004 paddy experiment. To avoid such a situation, we applied frequent irrigations during 2005 experiment that led to the application of over 5 times more irrigation water leaving only a maximum of 4 days of zero ponding condition. Total amounts of water shown in Table 2 are, however, within the typical range of 70$530 \mathrm{~cm}$ of water requirement reported for 100-day duration paddy varieties (Tuong and Bouman, 2003).

Table 2 also shows that Plots 4, 8, 10, and 12 consistently required more irrigation for both the years. We observed that almost in all plots there were earthworm casts in varying degree. Presence of such earthworm casts and holes may be a reason for rapid infiltration observed in these soils. Moreover, the occurrence of wetting and drying cycles may have led to the formation of small cracks and preferential pathways as was observed by Tournebize et al. (2006).

\subsection{Evidence of preferential flow in lowland paddy soil}

Although 12 experimental plots constituted a single patch of well leveled experimental field, the differential and often very high water requirement for maintaining ponding condition led to the hypothesis of loss of water either through rapid seepage and percolation or preferential flow; it may also be possible that both are occurring simultaneously. Seepage and percolation losses were expected to be minimal inasmuch as the bunds were laid out in 2004 summer just before the experiment and bunds were polished with mud each year before transplanting. However, we have not done any measurement to completely rule out seepage loss. To examine the hypothesis of preferential transport, we conducted a series of tension infiltrometer tests in each plot. Results were analyzed using both the steady-state and transient water flow approaches. Steady-state water flux densities at corresponding suction heads (Fig. 2) were used to optimize parameters $K_{\mathrm{s}}$ and $b$ (Table 3) for the Gardner's hydraulic conductivity function. Almost two orders of variation in $K_{\mathrm{s}}$ magnitudes may be observed for the surface soil both within a plot (Plot 5) and for the whole experimental area. The slope of the curves measured at locations

Table 2

Plot-wise total applied irrigation water $(\mathrm{cm})$ and total number of days on which no ponding was observed during July 25 till October 15 of the year 2004 and 2005.

\begin{tabular}{|c|c|c|c|c|}
\hline \multirow[t]{2}{*}{ Plot no. } & \multicolumn{2}{|c|}{$\begin{array}{l}\text { Total applied irrigation } \\
\text { water }(\mathrm{cm})\end{array}$} & \multicolumn{2}{|c|}{$\begin{array}{l}\text { Number of days having } \\
\text { zero ponding depth }\end{array}$} \\
\hline & 2004 & 2005 & 2004 & 2005 \\
\hline 1 & 82 & 566 & 32 & 4 \\
\hline 2 & 10 & 378 & 26 & 2 \\
\hline 3 & 40 & 483 & 27 & 3 \\
\hline 4 & 213 & 543 & 35 & 2 \\
\hline 5 & 65 & 495 & 31 & 2 \\
\hline 6 & 40 & 446 & 27 & 2 \\
\hline 7 & 124 & 632 & 38 & 1 \\
\hline 8 & 197 & 585 & 35 & 2 \\
\hline 9 & 39 & 489 & 26 & 2 \\
\hline 10 & 152 & 634 & 39 & 3 \\
\hline 11 & 40 & 597 & 27 & 2 \\
\hline 12 & 175 & 637 & 37 & 3 \\
\hline Mean & 98 & 540 & 32 & 2 \\
\hline
\end{tabular}

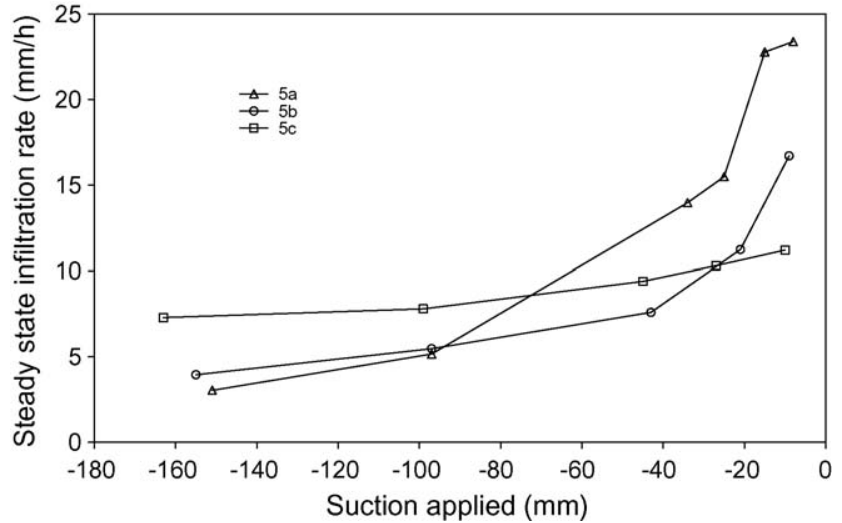

Fig. 2. Steady-state water infiltration rates measured as a function of applied suction head using a tension infiltrometer at three arbitrarily selected locations within Plot 5 during May 2005. The distance between two measurement locations was $1-2 \mathrm{~m}$.

$5 a$ and $5 b$ is larger than that for location $5 c$ at lower suction (close to zero value of suction head) suggesting that the infiltration rates near saturation for location $5 \mathrm{a}$ and $5 \mathrm{~b}$ are much higher than that for the location $5 c$. Larger $b$ values for the location $5 a$ and $5 b$ than $5 c$ support this observation. Table 3 also suggests that on an average about $52 \%$ of the total flux are through the mesopores plus macropores with a coefficient of variation (CV) of 30\%. Moreover, there is also a large variability within a plot (see for Plot 5). The average contribution of total water conducting pores in the present study is about an order of magnitude smaller than those reported by Watson and Luxmoore (1986) and Bodhinayake et al. (2004) except for TI measurements (e.g., Plot 5a) where high infiltration rate was observed.

Both Haws et al. (2004) and Langner et al. (1999) among others have shown that near-saturated soil condition is a pre-requisite for preferential flow to manifest. Large variation in $K_{\mathrm{s}}$, \%MF and $\theta_{\mathrm{mt}}$ within 1-2 $\mathrm{m}$ distance suggests that some of the plots could show rapid percolation but overall water loss from a specific plot (plotscale percolation) would depend on the relative abundance of preferential pathways present. Thus, it may be possible that the plot-scale percolation may be quite small even though a few preferential pathways are present within a plot. These results

Table 3

Parameters for the Gardner's unsaturated hydraulic conductivity function $\left[K(h)=K_{\mathrm{s}} \exp (b h)\right]$ and Watson and Luxmoore (1986) model for macroporosity. Suffices with a plot number indicates measurement locations within that plot.

\begin{tabular}{|c|c|c|c|c|c|}
\hline \multirow[t]{2}{*}{ Plot no. } & \multicolumn{3}{|c|}{$\begin{array}{l}\text { Parameters for the Gardner's } \\
\text { hydraulic conductivity model }\end{array}$} & \multicolumn{2}{|c|}{$\begin{array}{l}\text { Parameters for the Watson } \\
\text { and Luxmoore (1986) model }\end{array}$} \\
\hline & $K_{\mathrm{s}}\left(\mathrm{cm} \mathrm{day}^{-1}\right)$ & $b\left(\mathrm{~cm}^{-1}\right)$ & $R^{2}$ & $\theta_{\mathrm{mt}}\left(\times 10^{-5} \mathrm{~cm}^{3} \mathrm{~cm}^{-3}\right)$ & $M F(\%)$ \\
\hline 1 & 4.3 & 0.020 & 0.97 & 6.9 & 49 \\
\hline 2 & 6.7 & 0.038 & 0.99 & 5.5 & 48 \\
\hline $3 a$ & 0.6 & 0.004 & 0.99 & 3.0 & 52 \\
\hline $3 b$ & 10.5 & 0.046 & 0.91 & 8.9 & 52 \\
\hline 4 & 9.4 & 0.056 & 0.99 & 7.7 & 54 \\
\hline $5 a$ & 39.4 & 0.186 & 0.97 & 13.8 & 87 \\
\hline $5 b$ & 19.9 & 0.128 & 0.88 & 6.8 & 76 \\
\hline $5 c$ & 5.1 & 0.030 & 0.94 & 3.1 & 35 \\
\hline $6 a$ & 1.2 & 0.043 & 0.94 & 1.2 & 47 \\
\hline $6 b$ & 8.4 & 0.035 & 1.00 & 8.6 & 43 \\
\hline $7 a$ & 5.0 & 0.111 & 0.99 & 2.9 & 78 \\
\hline $7 b$ & 8.1 & 0.042 & 0.99 & 7.4 & 49 \\
\hline 8 & 9.6 & 0.046 & 1.00 & 11.7 & 66 \\
\hline 9 & 5.2 & 0.033 & 0.99 & 4.9 & 38 \\
\hline $10 a$ & 0.6 & 0.024 & 0.97 & 0.4 & 28 \\
\hline $10 \mathrm{~b}$ & 5.2 & 0.027 & 0.97 & 3.3 & 33 \\
\hline 11 & 11.4 & 0.038 & 0.96 & 10.0 & 47 \\
\hline 12 & 12.3 & 0.041 & 0.96 & 9.0 & 48 \\
\hline Mean & 9.1 & 0.053 & 0.97 & 6.0 & 52 \\
\hline
\end{tabular}




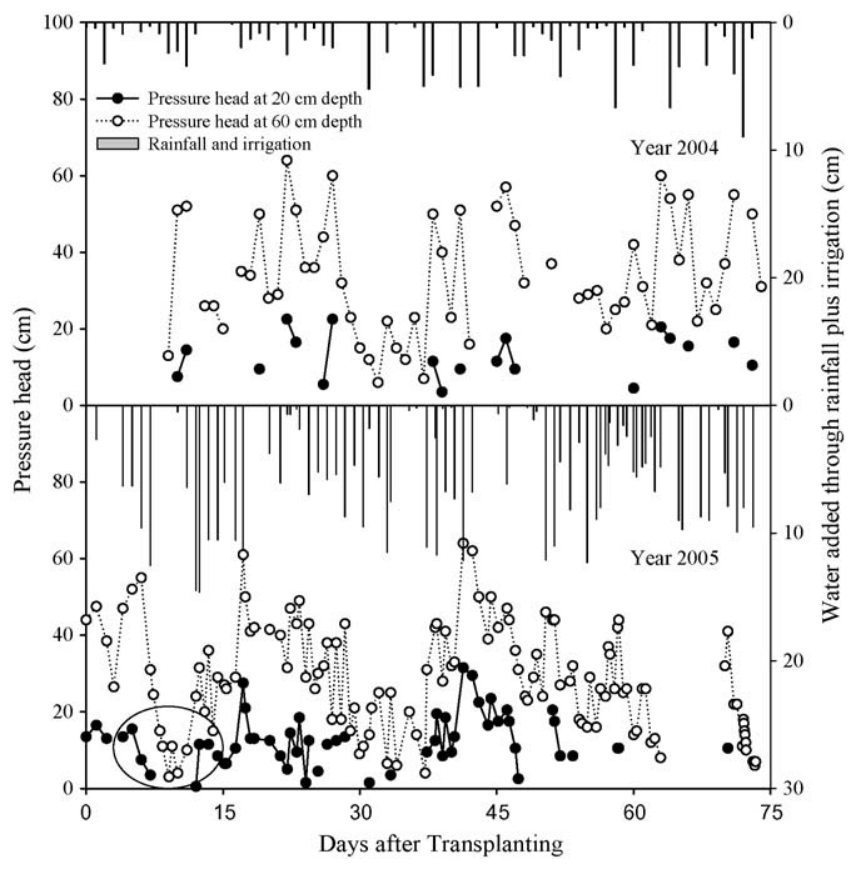

Fig. 3. Pressure head values measured at 20 and $60 \mathrm{~cm}$ soil depths in Plot 6 during 2004 and 2005 paddy growing season. Data enclosed by the parabola in the bottom panel is expanded in Fig. 6 to show the wetting and drying profiles of pressure head.

suggest that the plot-scale hydraulic properties with a greater support volume may be more important for modeling water flow in lowland paddy fields than those estimated by point measurement methods.

\subsection{Variation of pressure heads in soil profile}

During both the 2004 and 2005 paddy experiments, pressure head values at $20,40,60$, and $80 \mathrm{~cm}$ soil depths fluctuated depending on the net volume of water infiltrated through soil. Typical fluctuations for the pressure heads at 20 and $60 \mathrm{~cm}$ soil depths in Plot 6 are shown in Fig. 3. Also, shown are the total amount of water added through rainfall and irrigation in the secondary $y$-axes in this figure. Discontinuity in a pressure head time series suggests that the soil above that depth of measurement was partially saturated. Several discontinuities in the pressure

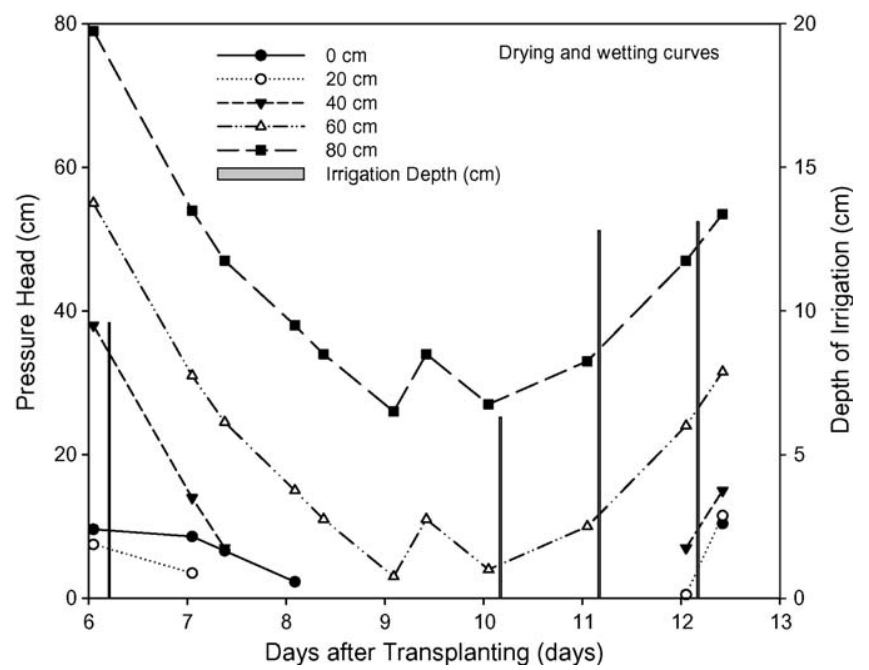

Fig. 4. Pressure head profiles measured at different depths in Plot 6 during 6-13 days after transplanting in 2005 experiment. This figure shows the piezometric response to drying and wetting events.

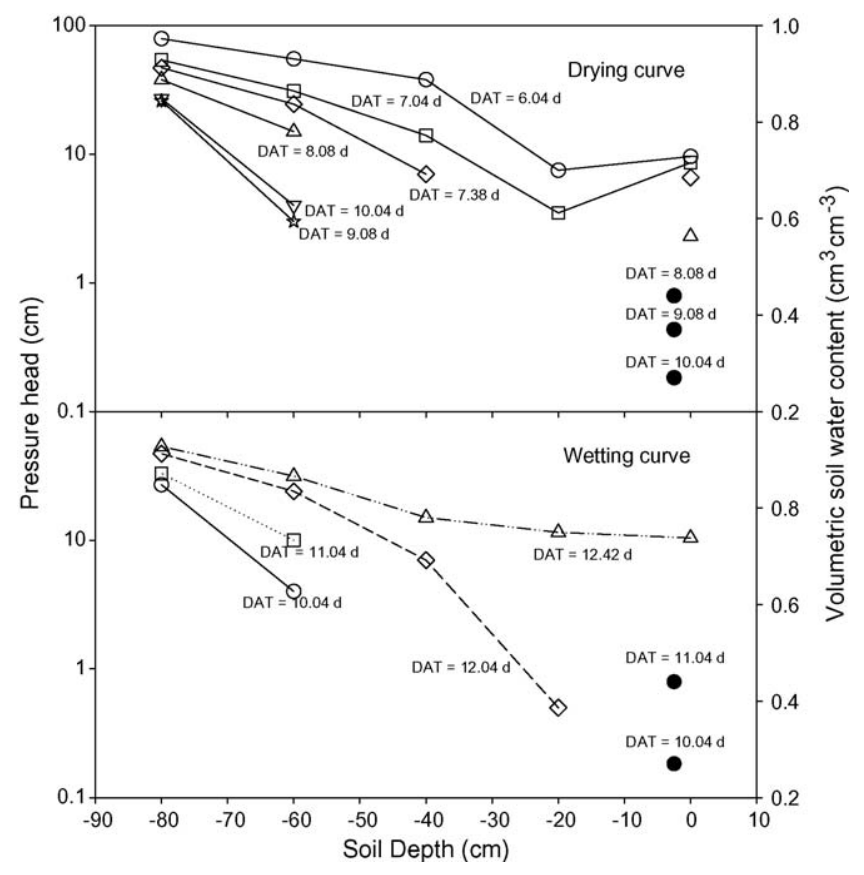

Fig. 5. Pressure head profiles measured at different times shown near each curve. Closed circles show the volumetric water contents in the soil samples collected from 0 to $5 \mathrm{~cm}$ soil depth.

head time series for the $20 \mathrm{~cm}$ depth (even with frequent water addition in 2005 experiment) suggest that soils around $20 \mathrm{~cm}$ depth and below the plow sole may get frequently unsaturated as is reported elsewhere (Wopereis et al., 1994). This aspect is exemplified in Figs. 4 and 6 (zoomed portion of the data enclosed by the parabola in Fig. 3), where we show pressure head variations as a result of drying and wetting cycle. Volumetric water contents estimated in the top $5 \mathrm{~cm}$ soil layer are also shown in Fig. 5. Fig. 4 shows that the soils at 60 and $80 \mathrm{~cm}$ depths remained saturated during the whole week, but those at 20 and $40 \mathrm{~cm}$ depths dried first ( 7.05 days after transplanting). As the dryspell continued for 4 days (from 6 DAT till 10 DAT), the ponded water from soil surface completely receded. During the drying phase, we gravimetrically estimated water contents in surface soil $(0-5 \mathrm{~cm})$, which indicated rapid decrease in soil wetness as the drying cycle continued. Volumetric water contents in top $5 \mathrm{~cm}$ soil were $0.44,0.37$, and $0.27 \mathrm{~cm}^{3} \mathrm{~cm}^{-3}$ on $8.38,9.08$, and 10.04 DAT, respectively (top panel of Fig. 5). Decrease in soil wetness from 0.44 to $0.27 \mathrm{~cm}^{3} \mathrm{~cm}^{-3}$ is equivalent to about $40 \%$ of water loss over a period of $35 \mathrm{~h}$ (8.38-10.04 DAT). In these soils, field capacity is reached in about $40 \mathrm{~h}$ with the loss of $50 \%$ of soil water. Similarly, water content in top $5 \mathrm{~cm}$ soil increased from 0.27 to $0.44 \mathrm{~cm}^{3} \mathrm{~cm}^{-3}$ on 11.04 DAT following wetting (bottom panel of Fig. 5). Fast approach to a wetness of $0.44 \mathrm{~cm}^{3} \mathrm{~cm}^{-3}$ following irrigation is common in these coarse textured soils. More interestingly, the pressure heads of deeper soil layers (60 and $80 \mathrm{~cm}$ soil depths) increase first suggesting that water must have reached these deeper layers rapidly bypassing the top $40 \mathrm{~cm}$ of soil. Such events are generally observed when preferential flow occurs (Haws et al., 2004). Similar results were observed for all the pressure head time series collected over two paddy growing cycles.

These results show that soils in lowland paddy field may get quickly wet or dry with rapid change in pressure head values (for example, pressure head on 12.04 DAT and 12.42 DAT). Second, water may rapidly percolate to deeper soil layers bypassing soil matrix as it occurs in preferential flow. This may be a result of soil's inherent ability to conduct more water either because of cracks developed during drainage cycle (Tournebize et al., 2006) or 


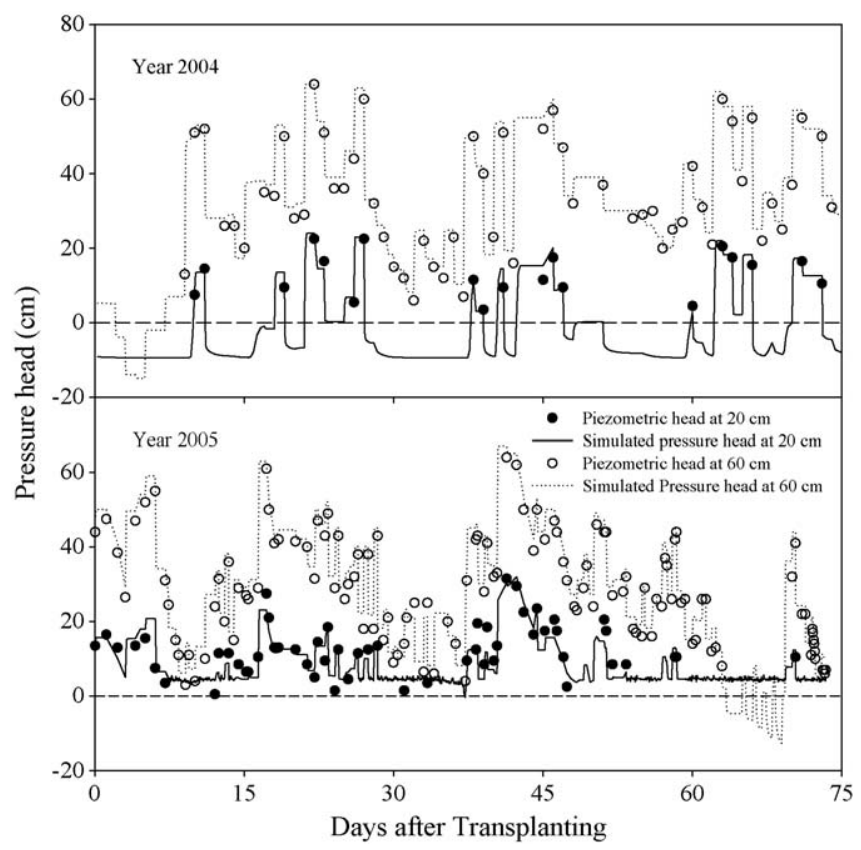

Fig. 6. Measured (symbols) and modeled (lines) pressure heads for 20 and $60 \mathrm{~cm}$ soil depths in Plot 6 during 2004 and 2005 paddy growing season. Modeled data were obtained by optimizing soil hydraulic properties using the single-porosity model.

earthworm holes made on plow sole (leaky plow sole). Third, soil layers both above the plow sole and above the clay pan (present in this soil at about $1 \mathrm{~m}$ soil depth) may temporarily show perched water tables, which may partially or completely dissipate as drying continues; soils above the plow sole would become unsaturated because of evapotranspiration and drainage as is shown by the decreasing soil wetness (closed circles). Similarly, the water table present above the clay pan would also recede as percolation (and possibly seepage) proceeds further with no water coming from top soil layers because of dryspell. Finally, even if soils remain saturated both at upper and lower soil layers, soils in between may get unsaturated (for example, curves representing 7.38 and 8.08 DAT).

\subsection{Modeling of water flow in lowland paddy soils}

Out of the total 72 sets of pressure head time series data, we estimated 96 sets ( 4 depth, 12 plots, and 2 growing season) of soil hydraulic parameters using both the SPM and DPM approach. In Fig. 6, we show modeled pressure head values for 20 and $60 \mathrm{~cm}$ soil depths shown in Fig. 3. Modeled data were obtained by optimizing soil hydraulic properties using the single-porosity model. Similar results were found for other 11 plots. Fig. 6 shows that the piezometric heads may be suitably modeled using the SPM approach. Similar results were also found for the DPM approach
Table 5

Comparison of saturated hydraulic conductivity $\left(K_{\mathrm{s}}\right)$ estimated in the presented study with those published by other researchers. Numbers in parenthesis are the average conductivities.

\begin{tabular}{llcl}
\hline Name & $\begin{array}{l}\text { Plow sole } \\
\text { depth (cm) }\end{array}$ & $K_{\mathrm{s}}\left(\mathrm{mmday}^{-1}\right)$ & Soil type \\
\hline Wopereis et al. (1992) & $15-20$ & $0.27-0.45(0.36)$ & $\begin{array}{l}38 \% \text { clay, 44\% silt, } \\
\text { and 18\% sand }\end{array}$ \\
Tuong et al. (1994) & $14-20$ & $1.2-3.3(2.3)$ & $\begin{array}{l}42 \% \text { clay, 44\% silt, } \\
14 \% \text { sand }\end{array}$ \\
Liu et al. (2001) & $20-30$ & $0.3-0.5$ & $\begin{array}{l}\text { Silty-loam } \\
\text { Chen and Liu (2002) }\end{array}$ \\
$\begin{array}{l}\text { Tournebize et al. (2006) } \\
\text { Present study }\end{array}$ & $17-23$ & $0.34-0.83(0.5)$ & $\begin{array}{l}\text { 90\% clay, 5-10\% sand } \\
\text { Alluvial lowland soil } \\
\text { Sandy loam }\end{array}$ \\
\hline
\end{tabular}

(data not shown) although it provided a slightly better description for about $50 \%$ of pressure head time series.

Estimated mean root-mean-squared error (RMSE) values in the SPM approach were 4.12 and $4.04 \mathrm{~cm}$ for the 2004 and 2005 pressure head data, respectively. Corresponding values in the DPM approach were 4.18 and $4.02 \mathrm{~cm}$. The average $R^{2}$ values for both the modeling approaches were 0.92 and 0.91 for the 2004 and 2005 data, respectively. In general, pressure head values for the $20 \mathrm{~cm}$ soil depth in both the modeling approaches were poorly described although the overall predictability for the whole profile was reasonable. The $R^{2}$ values for the $20 \mathrm{~cm}$ soil depth exceeded 0.6 only in $50 \%$ of the modeling results from both growing seasons in all modeling approaches.

Mean soil hydraulic parameters estimated from the SPM approach are listed in Table 4 for both the years along with their coefficient of variation (CV). In general, there was large variation for all the four parameters $\left(\theta_{\mathrm{r}}, \alpha, n\right.$, and $\left.K_{\mathrm{s}}\right)$ optimized in the SPM approach across different plots although the parameters $\alpha$ and $K_{\mathrm{s}}$ generally had greater variation than the parameter $n$. Variation in parameters along different soil layers within a given plot did not appear to be large except for the $K_{\mathrm{s}}$. Indeed, there was an order of magnitude reduction in $K_{\mathrm{s}}$ for $10-26 \mathrm{~cm}$ soil depth as compared to other layers supporting the presence of a compacted layer at this depth (average depth of $18 \mathrm{~cm}$ ). The development of a compacted plow sole with lower hydraulic conductivity at similar soil depth has also been reported (Table 5 ) by other researchers (Sharma and De Datta, 1985; Tuong et al., 1994; Chen et al., 2002). However, $K_{\mathrm{s}}$ values estimated in the present study are relatively larger than those reported in literature (Table 5). The reasons for this deviation may be twofold. First, our delineation of the plow sole is based on fewer bulk density measurements along a soil profile, which resulted in the assumption of a $16 \mathrm{~cm}$ thick plow sole compared to only $5-10 \mathrm{~cm}$ reported in the literature (Table 5). Second, we estimated a single set of hydraulic properties for the entire growing season unlike other studies (Wopereis et al., 1994; Tournebize et al., 2006). Therefore, the estimated $K_{\mathrm{s}}$ in the present study may have accounted for the effects of greater percolation volumes through macropores created because of wetting and

Table 4

Mean soil hydraulic parameters estimated using the single-porosity modeling approach

\begin{tabular}{|c|c|c|c|c|c|c|c|c|c|c|}
\hline \multirow[t]{2}{*}{ Soil layers $(\mathrm{cm})$} & \multicolumn{2}{|l|}{$\theta_{\mathrm{r}}\left(\mathrm{cm} \mathrm{cm}^{-3}\right)$} & \multicolumn{2}{|c|}{$\theta_{\mathrm{s}}\left(\mathrm{cm} \mathrm{cm}^{-3}\right)^{\mathrm{a}}$} & \multicolumn{2}{|l|}{$\alpha\left(\mathrm{cm}^{-1}\right)$} & \multicolumn{2}{|l|}{$n$} & \multicolumn{2}{|c|}{$K_{\mathrm{s}}\left(\mathrm{cm} \mathrm{h}^{-1}\right)^{\mathrm{b}}$} \\
\hline & 2004 & 2005 & 2004 & 2005 & 2004 & 2005 & 2004 & 2005 & 2004 & 2005 \\
\hline $0-10$ & $0.014(108)^{\mathrm{C}}$ & $0.045(83)$ & $0.44(6)$ & $0.44(6)$ & $0.150(96)$ & $0.077(21)$ & $2.32(35)$ & $1.54(27)$ & $0.38(45)$ & $0.38(45)$ \\
\hline $10-26$ & 0.035 (129) & $0.051(70)$ & $0.33(5)$ & $0.33(5)$ & $0.063(76)$ & $0.085(28)$ & $2.52(47)$ & $1.36(10)$ & $0.05(90)$ & $0.04(55)$ \\
\hline $26-52$ & $0.046(72)$ & $0.065(33)$ & $0.39(8)$ & $0.39(8)$ & $0.150(66)$ & $0.084(48)$ & $2.01(65)$ & $1.69(18)$ & $0.79(87)$ & $0.27(62)$ \\
\hline $52-80$ & $0.027(68)$ & $0.052(51)$ & $0.36(4)$ & $0.36(4)$ & $0.162(143)$ & $0.106(66)$ & $4.09(47)$ & $3.12(56)$ & $1.51(73)$ & $1.78(43)$ \\
\hline
\end{tabular}

a Estimated from measured bulk density and particle density.

b Saturated hydraulic conductivity for $0-10 \mathrm{~cm}$ depth is estimated from tension infiltrometer data. For all other depths, was estimated from pressure head data.

c Data presented in parentheses are coefficient of variation. 
Table 6

Mean soil hydraulic parameters estimated using the dual-porosity modeling approach.

\begin{tabular}{|c|c|c|c|c|c|c|c|c|c|c|c|c|}
\hline \multirow[t]{2}{*}{ Soil layers $(\mathrm{cm})$} & \multicolumn{2}{|c|}{$\theta_{\mathrm{sm}}\left(\mathrm{cm} \mathrm{cm}^{-3}\right)^{\mathrm{a}}$} & \multicolumn{2}{|l|}{$\alpha\left(\mathrm{cm}^{-1}\right)$} & \multicolumn{2}{|l|}{$n$} & \multicolumn{2}{|c|}{$K_{\mathrm{s}}^{\mathrm{b}}\left(\mathrm{cm} \mathrm{h}^{-1}\right)$} & \multicolumn{2}{|c|}{$\theta_{\operatorname{sim}}\left(\mathrm{cm} \mathrm{cm}^{-3}\right)^{\mathrm{a}}$} & \multicolumn{2}{|l|}{$\omega\left(\mathrm{h}^{-1}\right)$} \\
\hline & 2004 & 2005 & 2004 & 2005 & 2004 & 2005 & 2004 & 2005 & 2004 & 2005 & 2004 & 2005 \\
\hline $0-10$ & $0.13(6)^{\mathrm{c}}$ & $0.13(6)$ & $0.168(55)$ & $0.138(15)$ & $1.82(21)$ & $1.50(32)$ & $0.38(45)$ & $0.38(45)$ & $0.31(6)$ & $0.31(6)$ & $0.008(128)$ & $0.005(46)$ \\
\hline $10-26$ & $0.10(5)$ & $0.10(5)$ & $0.159(37)$ & $0.155(37)$ & $1.67(21)$ & $1.63(23)$ & $0.06(75)$ & $0.05(48)$ & $0.23(5)$ & $0.23(5)$ & $0.007(125)$ & $0.004(41)$ \\
\hline $26-52$ & $0.12(8)$ & $0.12(8)$ & $0.263(70)$ & $0.034(136)$ & $1.72(36)$ & 1.67 (37) & $0.34(66)$ & $0.33(73)$ & 0.27 (9) & $0.27(9)$ & $0.003(25)$ & $0.007(33)$ \\
\hline $52-80$ & $0.11(4)$ & $0.11(4)$ & $0.112(80)$ & $0.013(115)$ & $2.38(41)$ & $2.39(41)$ & $1.37(71)$ & $2.18(52)$ & $0.26(4)$ & $0.26(4)$ & $0.012(205)$ & $0.005(54)$ \\
\hline
\end{tabular}

a We assumed that $\theta_{\text {sim }}=0.3 \times$ porosity, $\theta_{\text {sm }}=0.7 \times$ porosity, $\theta_{\mathrm{rm}}=\theta_{\text {rim }}=0.0 \mathrm{~cm}^{3} \mathrm{~cm}^{-3}$.

b Saturated hydraulic conductivity for $0-10 \mathrm{~cm}$ depth is estimated from tension infiltrometer data. For all other depths, was estimated from pressure head data.

Data presented in parentheses are coefficient of variation.

drying effects or because of earthworm holes in surface soils as the growing season proceeded.

Mean soil hydraulic parameters estimated from the DPM are listed in Table 6 for both the years along with their coefficient of variation $(\mathrm{CV})$. In general, there was less variation for parameters optimized in the DPM approach across different plots compared to those estimated via the SPM approach although the $\alpha$ and $K_{\mathrm{s}}$ also had greater variation than $n$ as was observed with the SPM approach. As was observed with the SPM-estimated parameters, the saturated hydraulic conductivity of the $10-26 \mathrm{~cm}$ soil depth was lowest indicating the presence of a plow sole in this layer. The mass transfer rate coefficient $(\omega)$ ranged from 0.001 to $0.092 \mathrm{~h}^{-1}$ for different soil layers. Parameter $\omega$ was found to be quite uniform throughout the profile. Although from year to year there was no significant variation in soil hydraulic properties (as revealed by the Student's $t$-test), there was significant variation from plot to plot and within a profile.

To validate the parameter estimation method, we compared the observed pressure head values during 2005 experiment with those predicted using estimated hydraulic parameters estimated in the SPM approach from 2004 pressure head data. This yielded a mean RMSE value of $4.75 \mathrm{~cm}$ compared to mean RMSE $=4.04 \mathrm{~cm}$ obtained when the parameters were directly estimated using the 2005 data. Similar results were obtained when this protocol was reversed. Similar results were also obtained when the DPM approach was followed. We also estimated soil hydraulic properties for the whole profile (from soil surface down to $80 \mathrm{~cm}$ soil depth) using cumulative infiltration vs. time measured with the tension infiltrometer. Use of these parameters to predict

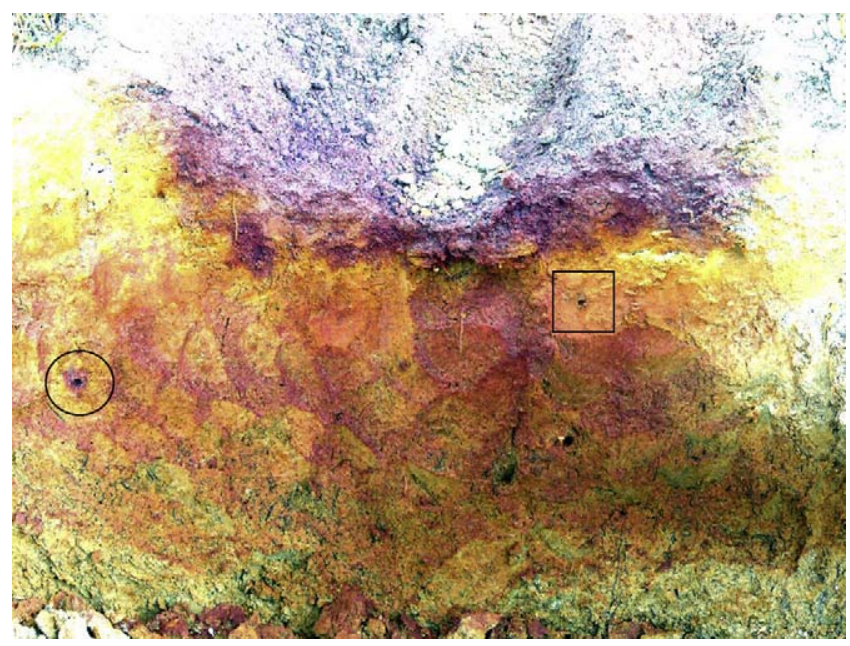

Fig. 7. Picture showing the cross-section of a soil profile after tracer was applied. The crimson red color of the cresol red indicator depicts the high $\mathrm{pH}$ condition resulted from soil being saturated by preferential transport of $\left(\mathrm{NH}_{4}\right)_{2} \mathrm{CO}_{3}$. The yellow color (due to thymol blue at low $\mathrm{pH}$ ) shows absence of $\left(\mathrm{NH}_{4}\right)_{2} \mathrm{CO}_{3}$. (For interpretation of the references to color in this figure legend, the reader is referred to the web version of the article.) pressure head values for individual layers for both the years (assuming a single set of hydraulic parameters for all layers) resulted in poor description of observed pressure head values. Thus, we surmised that the estimated parameters from TI measurements alone may not properly capture the layering effects on soil water dynamics. However, TI provided $K_{\mathrm{s}}$ for the surface soils, which we used as additional inputs for estimating hydraulic properties from the pressure head data measured in piezometers.

\subsection{Single-vs. dual-porosity modeling approach}

Simulation results for SPM and DPM showed that both the models could simulate water flow equally well in our experimental plots. We adopted the DPM framework with provision for preferential flow based on our observation on the presence of earthworm casts, high percolation rates (Table 2), and low mass transfer coefficients (Table 5). However, Fig. 2 showed that preferential flow paths are not present uniformly throughout a given plot. Similar results were also observed (Fig. 7) from a dye tracer study, which consisted of saturating the soil with $2 \%$ $\left(\mathrm{NH}_{4}\right)_{2} \mathrm{CO}_{3}$ solution followed by a mixture of $1 \%$ thymol blue and $1 \%$ cresol red (Wang et al., 2002). The crimson red color of the cresol red indicator depicts the high $\mathrm{pH}$ condition resulted from soil being saturated by preferential transport of $\left(\mathrm{NH}_{4}\right)_{2} \mathrm{CO}_{3}$. The yellow color (due to thymol blue at low $\mathrm{pH}$ ) shows absence of $\left(\mathrm{NH}_{4}\right)_{2} \mathrm{CO}_{3}$. Fig. 7 shows that the soil pore located at a greater depth from surface (enclosed by the circle) shows preferential breakthrough of the crimson red tracer whereas the pore located at a shallower depth (enclosed by a square) shows no tracer breakthrough. We also observed several instances of earthworms coiling to form a ball-like shape completely plugging the holes. Such cases mean that even preferential pathways exist, the continuity of drainage network (Deurer et al., 2003) will significantly influence the manifestation of preferential transport. Second, as was shown by Haws et al. (2004), preferential flow ceases to manifest as the flux density decreases even though a flow domain could contain preferential pathways (see Fig. 3 in Haws et al., 2004). Finally, the alternate wetting and drying cycles in our experiments may lead to a large range of water flux densities during the paddy growing cycle. While water may preferentially flow through the macropores during the wetting cycles in a near-saturated soil, it would move through the soil matrix during the drying cycles as soil desaturates. Thus, with frequent wetting and drying cycles a preferential flow model may inherently perform as well as a matrix flow model as the modeling approach adjusts for favouring both matrix and preferential flow as the respective condition of soil prevails. These reasons may be responsible for similar performance of the SPM and DPM approaches in this study.

\section{Conclusion}

Large quantity of water is needed for growing paddy and a better understanding of soil water regime is a key to manage 
such large water requirement. Recently, it is shown that physically based Richards equation may be used to describe soil water regime in paddy fields, but soil hydraulic properties are needed to solve Richards equations. Unsaturated soil water regimes develop in paddy fields as a result of puddling (Takagi, 1960) and alternate wetting and drying (Tournebize et al., 2006) conditions; the latter also occur as a part of monsoon climate in Eastern India. Vesicular structure of lateritic soils in eastern India, the presence of earthworm and other burrowing fauna, and cracking of soil as a result of alternate drying and wetting (Sander and Gerke, 2007) result in preferential flow paths in paddy soils making the characterization and estimation of soil hydraulic properties a challenging task. To comprehensively describe water flow in such soils, we conducted water flow studies in twelve $30 \mathrm{~m}^{2}$ plots during the rainy seasons (July to October) of 2004 and 2005. We observed that piezometric heads proportionally decrease as a result of the unsaturated condition in paddy fields. We took advantage of this quick piezometric response to estimate soil hydraulic properties using the Richards equation and the simulation environment of HYDRUS-1D.

Results indicated that a compacted plow sole develops because of puddling operation but it had a larger hydraulic conductivity range compared to those published in literature. Larger hydraulic conductivity of plow sole may be one of the several reasons for large infiltration volumes required in the present study. Profuse earthworm casts were found in each plot specifically during the early growth stage of paddy. Results from simulation studies suggest that both the single- and dual-porosity models could simulate water flow considerably well in lowland paddy field although the latter described pressure head time series data slightly better in about $50 \%$ of simulations. Similar performance of the single- vs. dual-porosity model may have resulted from estimating a seasonally mean soil hydraulic properties which includes the effect of both preferential flow and matrix flow as the specific soil and boundary conditions prevailed. While water may have preferentially transported through the macropores during the wetting cycles in a near-saturated soil, it would have dominantly moved through the soil matrix during the drying cycles. This study demonstrates that the piezometers may be effectively used to estimate hydraulic properties of different soil layers in a lowland paddy field. Measurement of piezometric heads even over a single growing season could provide a set of in situ hydraulic properties that may be used for predicting soil water regime in the lowland paddy fields.

\section{Acknowledgements}

We acknowledge the assistance provided by Mr. M.D. Patil in conducting the dye tracer study. We thankfully acknowledge several discussions we had with Mr. P. Santra during the preparation of the manuscript. The senior author acknowledges IIT, Kharagpur for providing research fellowship to conduct part of the study.

\section{References}

Belder, P., Bouman, B.A.M., Spiertz, J.H.J., 2007. Exploring options for water savings in lowland rice using a modelling approach. Agric. Syst. 92, 91-114.

Bodhinayake, W., Si, B.C., Xiao, C., 2004. New method for determining waterconducting macro- and mesoporosity from tension infiltrometer. Soil Sci. Soc. Am. J. 68, 760-769.

Cabangon, R.J., Tuong, T.P., 2000. Management of cracked soils for water saving during land preparation for rice cultivation. Soil Till. Res. 56, 105-116.

Chen, S.K., Liu, C.W., 2002. Analysis of water movement in paddy rice fields. (I) Experimental studies. J. Hydrol. 260, 206-215.

Chen, S.K., Liu, C.W., Huang, H.C., 2002. Analysis of water movement in paddy rice fields. (II) Simulation studies. J. Hydrol. 268, 259-271.
De Datta, S.K., 1987. Advances in soil fertility research and nitrogen management for lowland rice. In: Efficiency of Nitrogen Fertilizers for Rice, Int. Rice Research Institute, Los Baños, Philippines, pp. 27-41.

Deurer, M., Green, S.R., Clothier, B.E., Bottcher, J., Duijnisveld, W.H.M., 2003. Drainage networks in soils. A concept to describe bypass-flow pathways. J. Hydrol. 272, 148-162.

Garg, K.K., 2007. Measurement and modeling of water flow and nitrogen transport and transformation processes in lowland paddy field. PhD Thesis. Submitted to Indian Institute of Technology, Kharagpur, India.

Hardjoamidjojo, S., 1992. The effect of flooding and method of water application on water requirements and yield of wet land paddy. In: Murty, V.V.N., Koga, K. (Eds.), Soil and Water Engineering for Paddy Field Management. Proc. Int Workshop on Soil and Water Engineering for Paddy Field Management, Asian Inst. Technol., Bangkok, Thailand, 28-30 January 1992, pp. 63-71.

Haws, N.W., Das, B.S., Rao, P.S.C., 2004. Dual-domain solute transfer and transport processes: evaluation in batch and transport experiments. J. Contam. Hydrol. 75, 257-280.

Humphreys, L., Muirhead, W., Fawcett, B.J., Townsend, J., 1992. Minimizing deep percolation from rice. Farmers Newsletter (Griffith, NSW, Australia) 172, 41-43.

IRRI (International Rice Research Institute), 2004. Annual Report. IRRI, Los Baños, Philippines.

Janssen, M., Lennartz, B.B., 2007. Horizontal and vertical water and solute fluxes in paddy rice fields. Soil Till. Res. 94, 133-141.

Janssen, M., Lennartz, B.B., 2008. Characterization of preferential flow pathways through paddy bunds with dye tracer tests. Soil Sci. Soc. Am. J. 72, 1756-1766.

Janssen, M., Lennartz, B.B., 2009. Water losses through paddy bunds: methods, experimental data, and simulation studies. J. Hydrol. 369, 142-153.

Ladha, J.K., Fischer, K.S., Hossain, M., Hobbs, P.R., Hardy, B. (Eds.), 2000. Improving the productivity and sustainability of rice-wheat systems of the Indo-Gangetic Plains: a synthesis of NARS-IRRI partnership research. IRRI Discussion Paper Series No. 40. Int. Rice Research Institute, Los Baños, Philippines, 31 pp.

Langner, H.W., Gaber, H.M., Wraith, J.M., Huwe, B., Inskeep, W.P., 1999. Preferential flow through intact cores: effects of matric head. Soil Sci. Soc. Am. J. 63, 15911598.

Liu, C.W., Chen, S.K., Jou, S.W., Kuo, S.F., 2001. Estimation of the infiltration rate of a paddy field in Yun-Lin, Taiwan. Agric. Syst. 68, 41-54.

Panigrahi, B., Panda, S.N., Mal, B.C., 2001. Simulation of water harvesting potential in rainfed ricelands using water balance model. Agric. Syst. 69, 165-182.

Raun, W.R., Johnson, G.V., 1999. Improving nitrogen use efficiency for cereal production. Agron. J. 91, 357-363.

Sander, T., Gerke, H.H., 2007. Preferential flow patterns in paddy fields using a dye tracer. Vadose Zone J. 6, 105-115.

Sharma, P.K. De Datta, S.K., 1985. Puddling influence on soil, rice development, and yield. Soil Sci. Soc. Am. J. 49, 1451-1457.

Sharma, P.K., De Datta, S.K., 1992. Response of wetland rice to tropical conditions. In: Murty, V.V.N., Koga, K. (Eds.), Soil and Water Engineering for Paddy Field Management. Proc. Int. Workshop on Soil and Water Engineering for Paddy Field Management, Asian Inst. Technol., Bangkok, Thailand, 28-30 January 1992, pp. 107-109.

Simunek, J., van Genuchten, M.Th., 1997. Estimating unsaturated soil hydraulic properties from multiple tension disc infiltrometer data. Soil Sci. 162 (6), 383398.

Simunek, J., Sejna, M., van Genuchten, M.Th., 1999. The HYDRUS-2D Software Package for Simulating Two-dimensional Movement of Water, Heat, and Multiple Solutes in Variable Saturated Media. Version 2.0, IGWMC-TPS-53. International Ground Water Modeling Center, Colorado School of Mines, Golden, Colorado.

Simunek, J., Jarvis, N.J., van Genuchten, M.Th., Gardenas, A., 2003. Review and comparison of models for describing non-equilibrium and preferential flow and transport in the vadoze zone. J. Hydrol. 272, 14-35.

Tabbal, D.F., Bouman, B.A.M., Bhuiyan, S.I., Sibayan, E.B., Sattar, M.A., 2002. On-farm strategies for reducing water input in irrigated rice; case studies in the Philippines. Agric. Water Manage. 56, 93-112.

Takagi, S., 1960. Analysis of the vertical downward flow of water through a twolayered soil. Soil Sci. 90, 98-103.

Tournebize, J., Watanabe, H., Takagi, K., Nishimura, T., 2006. The development of a coupled model (PCPF-SWMS) to simulate water flow and pollutant transport in Japanese paddy fields. Paddy Water Environ. 4, 39-51.

Tuong, T.P., Bouman, B.A.M., 2003. Rice production in water-scarce environments. In: Kijne, J.W., Barker, R., Molden, D. (Eds.), Water Productivity in Agriculture: Limits and Opportunities for Improvement. CAB International, pp. 53-67.

Tuong, T.P., Wopereis, M.C.S., Marquez, J.A., Kropff, M.J., 1994. Mechanisms and control of percolation losses in irrigated puddled rice fields. Soil Sci. Soc. Am. J. $58,1794-1803$

Tuong, T.P., Bhuiyan, S.I., 1999. Increasing water-use efficiency in rice production: farm-level perspectives. Agric. Water Manage. 40, 117-122.

van Genuchten, M.Th., 1980. A closed-form equation for predicting the hydraulic conductivity of unsaturated soils. Soil Sci. Soc. Am. J. 44, 892-1037.

Vlek, P.L.G., Byrnes, B.H., Craswell, E.T., 1980. Effect of urea placement on leaching losses of nitrogen from flooded rice soils. Plant Soil. 54, 441-449.

Wang, Z., Lu, J., Wu, L., Harter, T., Jury, W.A., 2002. Visualizing preferential flow paths using ammonium carbonate and a pH indicator. Soil Sci. Soc. Am. J. 66 347-351.

Walker, S.H., Rushton, K.R., 1984. Verification of lateral percolation losses from irrigated rice fields by a numerical model. J. Hydrol. 71, 335-351. 
Watson, K.W., Luxmoore, R.J., 1986. Estimating macroporosity in a forest watershed by use of a tension infiltrometer. Soil Sci. Soc. Am. J. 50, 578582.

Wopereis, M.C.S., Bouman, B.A.M., Kropff, M.J., Berge, H.F.M.T., Maligaya, A.R., 1994 Water use efficiency of flooded rice fields. I. Validation of the soil-water balance model SAWAH. Agric. Water Manage. 26, 277-289.
Wopereis, M.C.S., Wosten, J.H.M., Bouma, J., Woodhead, T., 1992. Hydraulic resistance in puddled rice soils: measurement and effects on water movement. Soil Till. Res. 24, 199-209.

Yang, J., Liu, K., Wang, Z., Du, Y., Zhang, J., 2007. Water-saving and high-yielding irrigation for lowland rice by controlling limiting values of soil water potential. J. Integr. Plant Biol. 49, 1445-1454. 